\title{
PREVALENSI ABSENSI PALMARIS LONGUS TENDON SUKU LAMPUNG PADA CIVITAS AKADEMIKA UNIVERSITAS MALAHAYATI BANDAR LAMPUNG
}

\author{
M Fajrin Armin ${ }^{1}$, Sri Maria Puji Lestari ${ }^{2^{*}}$, Dicky Tama Jaya Pasa ${ }^{3}$ \\ 1,2Dosen Fakultas Kedokteran Universitas Malahayati \\ ${ }^{3}$ Mahasiswa Program Studi Kedokteran Universitas Malahayati \\ Email Koresponden: srimaria13pl@yahoo.com
}

\section{ABSTRACT: PREVALENCE OF THE PALMARIS LONGUS TENDON ABSENCES OF THE LAMPUNG TRIBE AT THE ACADEMIC CIVILITY OF MALAHAYATI UNIVERSITY BANDAR LAMPUNG}

Background : The development of the Palmaris Longus tendon is complete at birth. The Palmaris Longus tendon will not develop again after that. The Palmaris Longus tendon is often used for reconstructive surgery. The absence on one or both sides of the Palmaris longus tendon varies widely. Until now there has been no research on Palmaris Longus Absence in Lampung.

Objective : To determine the prevalence of Palmaris Longus Tendon Absence of Lampung Tribe in the Academic Community of Malahayati University, Bandar Lampung.

Methodology : This type of research is quantitative, with an observational design. The population of this research is the entire academic community of Malahayati University in Bandar Lampung, who are of Lampung ethnicity. Data were collected using total sampling technique. Physical examination used the Schaeffer test and confirmed by other physical examinations, namely the Mishra I test, Mishra II test, Thompson's test, Pushpakumar's two fingers sign.

Results : Of the 104 respondents, there were 6 Palmaris Longus Tendon attendances (5.8\%). Absence of unilateral palmaris longus tendons as many as 3 people (2.9\%), absence of bilateral palmaris longus tendons as many as 3 people (2.9\%), with male gender as many as 3 people (2.9\%), and female gender as many as 3 people (2.9\%).

Conclusion : The prevalence of Palmaris Longus Tendon Absence of the Lampung Tribe in the Academic Community of Malahayati University in Bandar Lampung is 6 people (5.8\%). Suggestions for further research in order to get results that more accurately represent the Indonesian population need more homogeneous and more subjects.

Keywords : Absence of Palmaris Longus Tendon, Lampung Tribe 


\section{INTISARI: PREVALENSI ABSENSI PALMARIS LONGUS TENDON SUKU LAMPUNG PADA CIVITAS AKADEMIKA UNIVERSITAS MALAHAYATI BANDAR LAMPUNG}

Latar Belakang : Perkembangan tendon Palmaris Longus sudah lengkap saat dilahirkan. Tendon Palmaris Longus tidak akan berkembang lagi sesudah itu. tendon Palmaris Longus sering digunakan untuk operasi rekonstruksi. Absensi pada satu atau ke dua sisi dari tendon Palmaris Longus sangat bervariasi. Hingga saat ini belum ada penelitian tentang Absensi Palmaris Longus di Lampung. Tujuan penelitian: Mengetahui Prevalensi Absensi Palmaris Longus Tendon Suku Lampung pada Civitas Akademika Universitas Malahayati Bandar Lampung.

Metode Penelitian : Jenis penelitian kuantitatif, dengan rancangan observasional. Populasi penelitian ini seluruh Civitas Akademika Universitas Malahayati Bandar Lampung yang bersuku Lampung. Data diambil menggunakan teknik Total Sampling. Pemeriksaan fisik menggunakan tes Schaeffer dan dikonfirmasi dengan pemeriksaan fisik lainnya yakni Tes Mishra I, Tes Mishra II, Tes Thompson, Pushpakumar's two fingers sign.

Hasil penelitian : Dari 104 responden Absensi Palmaris Longus Tendon sebanyak 6 orang (5,8\%). Absensi Palmaris Longus Tendon unilateral sebanyak 3 orang $(2,9 \%)$, Absensi Palmaris Longus Tendon Bilateral sebanyak 3 orang $(2,9 \%)$, dengan jenis kelamin laki-laki sebanyak 3 orang $(2,9 \%)$, dan jenis kelamin Perempuan sebanyak 3 orang $(2,9 \%)$.

Kesimpulan : Prevalensi Absensi Palmaris Longus Tendon Suku Lampung pada Civitas Akademika Universitas Malahayati Bandar Lampung sebanyak 6 orang $(5,8 \%)$. Saran untuk penelitian lebih lanjut agar mendapatkan hasil yang lebih akurat mewakili populasi Indonesia perlu subjek yang lebih homogen dan lebih banyak.

Kata Kunci : Absensi Palmaris Longus Tendon, Suku Lampung

\section{PENDAHULUAN}

Tendon Palmaris Longus merupakan salah satu tendon yang memiliki banyak variasi pada tubuh manusia. Tendon ini terletak antara m. flexor carpi radialis dan m.flexor carpi ulnaris, serta berguna untuk memfleksikan pergelangan dan menegangkan aponeurosis palmar. Namun, karena hanya sedikit berperan sebagai fleksor dan penegang aponeurosis, tendon ini tidak terlalu signifikan dalam mempengaruhi fungsi pergelangan. Oleh karena itu, jika tendon ini dicangkok, maka fungsi dan kekuatan lengan tidak akan terganggu. Pencangkokan tendon ini dapat digunakan dalam operasi rekonstruktif pada bagian bedah ortopedi dan bedah plastik (Mbaka, 2009).
Perkembangan tendon Palmaris Longus sudah lengkap saat dilahirkan (Vastamaki,1987) Tendon Palmaris Longus tidak akan berkembang lagi sesudah itu. Walaupun seperti fasia lata, tendon Palmaris Longus, sering digunakan untuk operasi rekonstruksi. Ada atau tidaknya tendon Palmaris Longus secara intensif diteliti pertama kali pada tahun 1559 oleh Colombos pada De Re Anatomica Libri. Beberapa penulis berpendapat bahwa ada atau tidaknya tendon Palmaris Longus merupakan vasiasi etnik. Penulis lain juga mencoba menghubungkan antara tidak adanya tendon Palmaris Longus dengan anomali anatomi yang lain, seperti anomali dari arcus palmaris superfisialis dan tidak adanya tendon plantaris. Tidak adanya pada satu atau ke dua sisi dari tendon Palmaris Longus sangat bervariasi. Beberapa penulis 
berpendapat bahwa tidak adanya tendon Palmaris Longus umumnya terdapat pada wanita, tidak adanya tendon Palmaris Longus bilateral lebih sering pada wanita, dan bila unilateral lebih sering tidak terdapat pada sisi kiri (Sebastin, 2006).

Hingga saat ini belum ada literatur memberikan jawaban pasti tentang faktor apa saja yang mempengaruhi ketiadaan tendon Palmaris Longus. Beberapa literatur mengatakan gender, ras, keturunan, serta sisi merupakan faktor yang dapat mempengaruhi ketiadaan Palmaris Longus. Namun, pada penelitianpenelitian lain yang dilakukan, ternyata hasilnya tidak signifikan mendukung hipotesis di atas (Thompson et al, 2001). Tendon Palmaris Longus ini bisa tidak ditemukan dan tergantung pada ras. Variasi tendon plamaris longus berhubungan dengan morfologi, origo, insersi, dan persarafannya. Ada dan tidaknya tendon plamaris longus pada tiap individu berbeda. Tendon Palmaris Longus dapat tidak ditemukan unilateral atau bilateral.

Pada literatur di Malaysia 2.8-24\% dari populasi tidak terdapat tendon Palmaris Longus. Tidak ada tendon Palmaris Longus unilateral pada 6.4\%, tidak ada tendon Palmaris Longus bilateral 2.9\%. Secara keseluruhan tidak adanya tendon Palmaris Longus sebanyak 9.3\%, secara terperinci di Malaysia terdapat multirasial, Kaukasia mempunyai rata-rata tertinggi tidak adanya tendon Palmaris Longus yaitu antara 12-24\%, Cina, Singapura mempunyai rata-rata $4.6 \%$ Pada penelitian yang lain, populasi Cina yang tidak memiliki tendon Palmaris Longus sebesar 2.8\%, dan Amazon Indian sebesar 3,7\%. Penelitian lain pada populasi Nigeria tidak adanya tendon Palmaris Longus unilateral sebesar $12.5 \%$, dan tidak terdapat tendon Palmaris Longus bilateral 18.75\%. Pada studi populasi Kaukasia, tidak terdapat tendon Palmaris Longus bilateral 9\%, tidak terdapat tendon Palmaris Longus unilateral 16\% (Fazan, 2007).

Berdasarkan uraian diatas, penulis tertarik untuk meneliti lebih lanjut mengenai Prevalensi Tendon Palmaris Longus Suku Lampung pada Civitas Akademika Universitas Malahayati dikarenakan belum adanya penelitian mengenai prevalensi Tendon Palmaris Longus pada Universitas Malahayati dan belum adanya data yang jelas mengenai jumlah data prevalensi Tendon Palmaris Longus pada Universitas Malahayati.

\section{METODE PENELITIAN}

Penelitian ini dilakukan untuk mencari prevalensi tendon Palmaris Longus Suku Lampung pada Civitas Akademika Universitas Malahayati. Oleh karena itu penelitian ini adalah satu penelitian dengan desain observasional menggunakan variabel kategorik yang tidak berpasangan.

Populasi dalam penelitian ini seluruh Civitas Akademika Universitas Malahayati Bandar Lampung yang bersuku Lampung sejumlah 104 orang. Sampel yang diambil dalam penelitian ini diambil dengan menggunakan teknik Total Sampling yaitu Civitas Akademika Universitas Malahayati Bandar Lampung yang bersuku Lampung sebanyak 104 orang. Variabel dalam penelitian ini yaitu tendon Palmaris Longus.

Metode pengumpulan data menggunakan data primer, karakteristik responden (jenis kelamin) diperoleh dengan melakukan wawancara langsung. Pemeriksaan fisik yang dilakukan dalam menilai absensi dari Palmaris Longus adalah dengan inspeksi dan palpasi menggunakan tes Schaeffer. Jika Palmaris Longus tidak teridentifikasi dengan pemeriksaan tersebut, maka absensi Palmaris Longus dikonfirmasi dengan pemeriksaan fisik lainnya yakni Tes Mishra I, Tes Mishra II, Tes 
Thompson, Pushpakumar's two fingers sign. Analisa univariat menggunakan bantuan program komputer.

\section{HASIL PENELITIAN}

Pengumpulan data dilakukan selama 1 bulan yaitu pada bulan September 2020 di Universitas Malahayati Bandar Lampung yang dilakukan terhadap 104 Civitas Akademika Universitas Malahayati Bandar Lampung yang bersuku Lampung, dengan hasil penelitian sebagai berikut:

1. Jenis Kelamin

Tabel 1 Distribusi frekuensi Jenis Kelamin

Responden Suku Lampung

\begin{tabular}{ccc}
\hline $\begin{array}{c}\text { Jenis } \\
\text { Kelamin }\end{array}$ & $\begin{array}{c}\text { Jumlah } \\
(\mathbf{n})\end{array}$ & $\begin{array}{c}\text { Persentase } \\
(\mathbf{\%})\end{array}$ \\
\hline - Laki-laki & 34 & $32,7 \%$ \\
- & 70 & $67,3 \%$ \\
Perempuan & & \\
\hline
\end{tabular}

Berdasarkan tabel 1 di atas didapatkan dari 104 responden sebagian besar responden berjenis kelamin perempuan yaitu sebanyak 70 responden $(67,3 \%)$.

\section{Absensi Palmaris Longus Tendon Tabel 2 Distribusi frekuensi \\ Prevalensi Absensi \\ Palmaris Longus Tendon}

\begin{tabular}{lcc}
\hline $\begin{array}{c}\text { Palmaris } \\
\text { Longus } \\
\text { Tendon }\end{array}$ & $\begin{array}{c}\text { Jumla } \\
\mathbf{h}(\mathbf{n})\end{array}$ & $\begin{array}{c}\text { Persentas } \\
\text { e (\%) }\end{array}$ \\
\hline $\begin{array}{l}\text { Presensi } \\
\text { Absensi: }\end{array}$ & 98 & $94,2 \%$ \\
- Unilatera & 3 & $2,9 \%$ \\
I & 3 & $2,9 \%$ \\
- Bilateral & & \\
\hline \multicolumn{1}{c}{ Total } & 104 & $100,0 \%$ \\
\hline
\end{tabular}

Berdasarkan tabel 2 di atas didapatkan dari 104 responden yang terdapat
Palmaris Longus Tendon sebanyak 98 responden (94,2\%), sedangkan yang mengalami Absensi Palmaris Longus Tendon unilateral sebanyak 3 responden $(2,9 \%)$, Absensi Palmaris Longus Tendon Bilateral sebanyak 3 responden $(2,9 \%)$.

3. Absensi Palmaris Longus Tendon Berdasarkan Sisi Tangan Yang Terhubung

Tabel 3 Distribusi frekuensi Absensi Palmaris Longus Tendon Berdasarkan Sisi Tangan Yang Terhubung

\begin{tabular}{lcc}
\hline & $\begin{array}{c}\text { Jumla } \\
\text { h (n) }\end{array}$ & $\begin{array}{c}\text { Persenta } \\
\text { se (\%) }\end{array}$ \\
\hline Laki-laki: & & \\
- Unilater & 1 & $1.0 \%$ \\
al & 2 & $1.9 \%$ \\
- Bilateral & & \\
Perempu & 2 & $1.9 \%$ \\
an: & 1 & $1.0 \%$ \\
- Unilater & & \\
$\quad$ al & & \\
- Bilateral & & \\
\hline Total & 6 & $5,8 \%$ \\
\hline
\end{tabular}

Berdasarkan tabel 3 di atas yang tidak memiliki tendon palmaris longus bilateral adalah 2 orang lakilaki $(1,9 \%), 1$ orang wanita $(1,0 \%)$, dan yang hanya mempunyai satu tendon palmaris longus 1 orang laki-laki $(1,0 \%), 2$ orang wanita $(1,9 \%)$.

\section{PEMBAHASAN}

Dari 104 responden Absensi Palmaris Longus Tendon sebanyak 6 orang (5,8\%). Absensi Palmaris Longus Tendon unilateral sebanyak 3 orang $(2,9 \%)$, Absensi Palmaris Longus Tendon Bilateral sebanyak 3 orang $(2,9 \%)$, dengan jenis kelamin laki-laki sebanyak 3 orang $(2,9 \%)$, dan jenis kelamin Perempuan sebanyak 3 orang $(2,9 \%)$. 
Ketiadaan tendon palmaris longus ini bisa tergantung pada ras. Variasi tendon palmaris longus berhubungan dengan morfologi, origo, insersi, dan persarafan-nya. Ada dan ketiadaan tendon plamaris longus pada tiap individu berbeda. Ketiadaan tendon palmaris longus dapat ditemukan unilateral atau bilateral. Tendon Palmaris Longus merupakan tendon fleksor lengan bawah, yang terletak superfisial. Tendon ini memiliki origo di epicondylus medialis dan insersio di retinaculum flexorum dan aponeurosis palmar. Tendon Palmaris Longus terletak antara tendon flexor carpi radialis dan flexor carpi ulnaris. Bentuk tendon Palmaris Longus adalah ramping dan fusiformis (Roohi, 2007). Tendon ini telah terbentuk sempurna sejak lahir, dan ada kemungkinan diturunkan secara genetik, namun belum jelas gen dan bagaimana transmisi genetiknya (Agarwal, 2005).

Menurut literatur prevalensi ketiadaan tendon Palmaris Longus adalah sekitar $15 \%$ di Dunia. Berdasarkan penelitian-penelitian sebelumnya yang diteliti pada beberapa ras dan etnis yang berbeda, ternyata menunjukkan angka yang bervariasi. Angka yang lebih tinggi dilaporkan pada ras kaukasia Amerika Utara, yaitu 24\%. Survey di Pennsylvania, Amerika Serikat menunjukkan prevalensi 23\%. Ceyhan dan Mav, melaporkan angka yang jauh lebih tinggi pada populasi Gaziantep di Turki, yaitu 63,9\%. Studi yang dilakukan pada populasi Jepang menunjukkan bahwa prevalensi ketiadaan tendon Palmaris Longus adalah 3,4\%. Pada Populasi Uganda disebutkan bahwa prevalensi ketiadaannya adalah 1,02\% (Mbaka, 2009). Dan Berdasarkan penelitian Hadi (2015) prevalensi ketiadaan Palmaris Longus pada populasi Indonesia secara keseluruhan adalah 10,4\% (bilateral 37,5\% dan unilateral $62,5 \%)$.
Penelitian terhadap 120 orang laki-laki, dan 209 orang perempuan berusia sekitar 7-85 tahun di Cina mendapatkan hasil bahwa, ketiadaan Palmaris Longus di Cina pada laki-laki angka kejadiannya lebih banyak dibandingkan perempuan, ketiadaan unilateral kiri lebih banyak bila dibandingkan dengan ketiadaan unilateral kanan, ataupun bilateral. Namun, setelah dilakukan perhitungan statistik, tidak ada perbedaan yang signifikan baik dilihat dari jenis kelamin, maupun sisi tubuh. Pada penelitian ini tendon Palmaris Longus ditemukan dengan melakukan uji Standard (Uji Schaeffer), Thompson, Mishra I, Mishra II, dan Pushpakumar "the two finger sign"(Sebastin et al, 2006).

Penelitian terhadap 335 orang laki-laki dan 265 orang perempuan berusia antara 8-65 tahun di Yoruba mendapatkan hasil bahwa, ketiadaan Palmaris Longus di Yoruba pada lakilaki angka kejadiannya lebih banyak dibandingkan perempuan, ketiadaan unilateral kiri lebih banyak bila dibandingkan dengan ketiadaan unilateral kanan, ataupun bilateral. Namun, setelah dilakukan perhitungan statistik, tidak ada perbedaan yang signifikan baik dilihat dari jenis kelamin, maupun sisi tubuh. Pada penelitian ini tendon Palmaris Longus ditemukan dengan melakukan uji Standard (Uji Schaeffer), Thompson, Mishra I, dan Pushpakumar "the two finger sign” (Mbaka et al, 2009).

Ketiadaan Palmaris Longus di India pada laki-laki angka kejadiannya lebih banyak dibandingkan perempuan, ketiadaan unilateral kiri lebih banyak bila dibandingkan dengan ketiadaan unilateral kanan, ataupun bilateral. Namun, setelah dilakukan perhitungan statistik, tidak ada perbedaan yang signifikan baik dilihat dari jenis kelamin, maupun sisi tubuh. Pada penelitian ini tendon Palmaris Longus ditemukan dengan melakukan uji Standard (Uji Schaeffer), Mishra I, 
Mishra II, dan Pushpakumar "the two finger sign” (Agarwal, 2005).

Dari hasil literatur dan penelitian, prevalensi adanya tendon otot palmaris longus bervariasi tergantung populasinya, tendon palmaris longus dari segi umur tidak dapat dibedakan karena tendon palmaris longus memang sudah terbentuk sempurna sejak dilahirkan. Pada penelitian ini hanya ingin mengetahui seberapa banyak yang tidak mempunyai tendon palmaris longus karena sangat banyak variasi dari tendon palamaris longus ini. Selain itu tendon ini penting untuk material operasi rekonstruksi karena tendonnya yang panjang, seperti digunakan pada berbagai perbaikan kerusakan dari kepala dan leher, ptosis pada anak, arthritis dari ibu jari dengan reseksi trapezium dan opponensplasty dari cedera akut tendon thenar.

Hasil penelitian ini menunjukkan bahwa Prevalensi Absensi Palmaris Longus pada Suku Lampung yaitu $5,8 \%$, sejalan dengan penelitian Hadi (2015) yang menunjukkan Prevalensi Palmaris Longus pada enam Suku di Indonesia berkisar antara 4,1\%-15,5\% yaitu Suku Minang 4,1\%, Suku Betawi 5,7\%, Suku Jawa 10,0\%, Suku Sunda 11,8\%, Suku Madura 15,4\%, dan Suku Batak 15,5\%.

\section{KESIMPULAN DAN SARAN \\ Kesimpulan}

Prevalensi Absensi Palmaris Longus Tendon Suku Lampung pada Civitas Akademika Universitas Malahayati Bandar Lampung dari 104 responden sebanyak 6 orang $(5,8 \%)$. Absensi Palmaris Longus Tendon unilateral sebanyak 3 orang (2,9\%), Absensi Palmaris Longus Tendon Bilateral sebanyak 3 orang $(2,9 \%)$, dengan jenis kelamin laki-laki sebanyak 3 orang $(2,9 \%)$, dan jenis kelamin Perempuan sebanyak 3 orang $(2,9 \%)$

\section{Saran}

1. Bagi penelitian lebih lanjut agar mendapatkan hasil yang lebih akurat mewakili populasi Indonesia perlu subjek yang lebih homogen dan lebih banyak.

2. Bagi masyarakat, hasil penelitian ini diharapkan dapat menjadi informasi mengenai Prevalensi Absensi Palmaris Longus Tendon Suku Lampung

3. Bagi institusi pendidikan, hasil penelitian ini diharapkan dapat menjadi referensi bagi ilmu anatomi dan fisiologi.

\section{DAFTAR PUSTAKA}

Agarwal, A., \& Agarwal, R. (2005) An unusual farm injury: divergent carpometacarpal joint dislocations. Journal of Hand Surgery, 30(6), 633-634.

Dabov, G., Perez, E. A., \& Canale, S. T. (2003). Campbell's operative orthopaedics. Mosby, Philadelphia.

Dahlan, M. S. (2011). Statistik untuk kedokteran dan kesehatan. Penerbit Salemba.

Fazan VPS. (2007). Reversed Palmaris Longus Muscle and Median Nerve Relationships.Case Report and Literature Review. Braz J Morphol Sci;24(2):28-31

Hadi, S. A., \& Masri, D. P. (2015). Palmaris longus absence in six largest Indonesian ethnicities and its relationship with gender, ethnicity, and hand dominance. Medical Journal of Indonesia, 24(1), 24-9.

Hastono, Susanto Priyo (2017). Modul Analisis Data Fakultas Kesehatan Masyarakat. Universitas Indonesia.

Kayode AO, Olamide AA, Blessing OI, et al. (2008). Incidence of Palmaris Longus Muscle Absence in Nigerian Population: 1-4. Tersedia: www.scielo.cl/pdf/ijmorphol/ 
v26n2/art09.pdf

September 2010).

$(16$

Marieb, E. N., Hoehn, K., Wilhelm, P. B., \& Zanetti, N. (2006). Human Anatomy \& Physiology: International Edition with Human Anatomy and Physiology Atlas, 7/E.

Mbaka, G. O., \& Ejiwunmi, A. B. (2009). Prevalence of palmaris longus absence-a study in the Yoruba population. The Ulster medical journal, 78(2), 90.

Notoatmodjo, S. (2018). Metodologi penelitian kesehatan (Cetakan VI). Jakarta: Penerbit PT. Rineka Cipta.

Oomman RA, Rajarajeshwari. (2002). Palmaris Longus-Upside Down: 1-3.

Tersedia: medind.nic.in/jae/t02/i2/jaet 02i2p232.pdf (14 September 2010).

Riyanto, A. (2011). Aplikasi metodologi penelitian kesehatan. Yogyakarta: Nuha Medika, 216.

Roohi, S. A., Choon-Sian, L., Tan, G. H., Naicker, A. S., \& Med Rehab, M.. A study on the absence of palmaris longus in a multiracial population. Malaysian Orthopaedic Journal, 1(1), 2007; 26-28.

Sebastin SJ, Lim AYT, Wong HB. (2006). Clinical Assessment of absence of the Palmaris longus and its association With Other Anatomical Anomalies- A Chinese Population Study, Singapore Ann Acad Med. 35: 249-53

Thompson NW, Mockford BJ, Cran GW. (2001). Absence of the palmaris longus muscle: a population study. The Ulster J Med. 70(1):.22-24.

Vastamäki, M. (1987). Shoulder arthrodesis for paralysis and arthrosis. Acta orthopaedica Scandinavica, 58(5), 549-553.
Wehbe MA. (1995). Tendon Graft Donor Site: 1-4. Tersedia: http: / /www.ncbi.nlm.nih.gov /pubmed/1430954. 